\title{
Social proof in social media shopping: An experimental design research
}

\author{
Yurita Yakimin Abdul Talib ${ }^{1, *}$ and Rafeah Mat Saat ${ }^{1}$ \\ ${ }^{1}$ Tunku Puteri Intan Safinaz School of Accountancy, Universiti Utara Malaysia, Malaysia
}

\begin{abstract}
The practices of social proof techniques to attract consumers to shop on social media have proliferated over time and been used extensively. The reviewed literature uncovers that social community recommendation, customers' ratings and reviews, celebrity's endorser and numbers of likes, affect consumers' purchasing decisions. However, the effect of different types of social proof techniques on purchasing intention is unknown. This study empirically compares the effect of number of followers, celebrity endorser and social community recommendation on consumers' purchasing intention. An experiment has been conducted and the results reveal that the consumers' purchasing intention differs between groups. Further analysis discovers that the impact on consumers' purchasing intention is different between high number of followers and low number of followers, and between having social community recommendation and not having social community recommendation. Though, the impact of these two techniques is equal wherein no technique is superior to other. In order to gain purchasing engagement and boost online sales, online businesses on social media are encouraged to use the power of social proof technique, either by increasing the number of followers or providing more social community recommendations.
\end{abstract}

\section{INTRODUCTION}

The evolution of the Internet and its related technology has created new forms of interactions for acquisition of goods and services through social networking platforms, such as Facebook, Instagram, Twitter, WhatsApp, and Telegram. Online shopping has migrated from the web sites shopping experience to social media shopping experience. An online shopping engagement via social media is created by means of customers' reviews, social community recommendations, referrals and customers' ratings. The rise of social media allows users to share and access information within the social community [1]. Online buyers' reliance on social community shared information, a kind of social proof techniques, is generally useful and effective at increasing consumer trust [2]. Trust formation from trusted sources is the key to a successful online purchasing engagement $[3,4]$.

Social proof techniques are generally effective at increasing consumer trust on online purchase. Amblee and Bui [2] discovered that electronic word-of-month (eWOM) among social community, such as online ratings and reviews, is a useful and effective signal of product reputation for a shopper yet to have a purchasing experience. Social interaction of consumers in the social media leads to increased trust to the online sellers and intention to buy [5]. Social media enables sellers to interact directly with their potential buyers and help them to understand their customers' social habits in order to engage conversion with them, which ultimately will help to increase sales. Social media also allows customers to review and evaluate their purchased product, and thus provides information to other people in their social community [6]. As a number of positive reviews and recommendations grow, consumers have more favorable attitude toward a product [7]. Hence, firms are encouraged to use various social proof techniques offered by social media to drive consumers' purchase $[8]$.

Although prior studies have uncovered the benefits of social proof techniques, there is no yet study on comparing the techniques and determining the most effective technique. This study seeks to extend prior studies by exploring the

\footnotetext{
* Corresponding author: yurita@uum.edu.my
} 
following research question: Are different types of social proof techniques are equally effective in influence consumers' purchase intention in a social commerce site? The answer to the question will have practical implications for online business in general and social commerce business specifically.

\section{LITERATURE REVIEW}

\subsection{Social Media}

Social media is defined as a group of internet-based applications that build on Web 2.0 technology that allows for the 0creation and exchange of User Generated Content [9]. Similarly, Parr [10] defines social media as a use of Internet or Web-based technologies to share and discuss information with users across the globe. The Web 2.0 technology enables users from various platforms to create, discuss and share content within the community to create social networks. Hence, the fundamental elements of social media are Web 2.0, content (information) and community. Other elements of social media are openness, accessibility and speed of information. Openness indicates that anyone can join almost all social media platforms for free [11]. The contents on social media platforms are shared instantaneously and accessed by anyone in the social community anywhere and anytime [12].

According to Mayfield [11], social media can be classified into seven types, such as social networks sites (SNSs), forums, blogs, podcasts, wikis, content communities and microbloggings. SNSs are websites that allows people to connect virtually with their real world friends and families to form their social community [11]. Facebook and Instagram are examples of SNSs. Blogs are online journals (normally personal) that contain text, images, audio and video that are shared in the Internet and owned by bloggers. Blogs allow the bloggers and readers to communicate online and form a community [11]. Another type of social media is Wikis, a website that allows users to add, modify and delete contents. Wikipedia, an online encyclopedia, is the most popular Wiki website. The Internet forum starts with a group of people share and discusses a same topic or interest. The discussion on the forum, known as thread, can be triggered by any members of the forum community [11]. Unlike blogs, there is no ownership for the forums.

The emergence of social media has gained tremendous popularity and is widely accepted as a new form of interactions. Across the world, there were 21.6 billion users of the social media in 2015, and it is expected to grow [13]. Accordingly, social networking was the second most popular activities among Malaysian internet users [14].

\subsection{The Evolution of Social Commerce}

Online shopping or e-commerce is a common trend in society nowadays. Online shopping is described as purchasing products or services via the Internet. In 2014, one-quarter of 300,000 global respondents were users of e-commerce and more than half $(55 \%)$ are willing to use it in the future [15]. Malaysians are ranked among the most passionate online shoppers. By 2015, Malaysia's online shopping market is expected to increase to RM5 billion (US\$1.52 billion) [15]. Variety of products could be purchased online easily including tickets, clothing items, home accessories, electronic gadgets, foods, and many more. Shopping activities over the internet has been part of the lifestyle due to the advantages offered by online services. For instance, individuals are attracted to shop online due to wider products selection, cost and time saving, as well as convenient shopping experience [16].

One of the major developments in the e-commerce industry recently is social media shopping or social commerce that is expected to evolve as a widely acceptable practice. "Social commerce is no longer media hype or a business fad. It becomes an established practice, although the specifics of this practice continue to emerge and evolve" [17](Wang and Zhang, 2012, p. 121). Social media shopping has received a tremendous role in changing the way people shop nowadays. Shopping via social media platforms such as Facebook and Instagram has taken over in-store shopping experience. The rise of social media shopping is contributed by the increased of social media users. Across the world, there were 21.6 billion users of the social media in 2015, and it is expected to grow [13]. Accordingly, social networking was the second most popular activities among Malaysian internet users [14].

As a subset of e-commerce, social commerce involves commercial activities, such as marketing, selling and buying products and services, using social media technologies to support online interactions and user contributions [18]. The interactions among the social media users may result in discovering products, aggregating and sharing product information, and collaboratively making shopping decisions [19]. In essence, the two important attributes of social commerce are commercial activities and social networks. The capability of social networks that allows for users' content participation, such as reviews and recommendations, for example, represents the major advantages of social commerce [18]. These social proof techniques increased consumers trust towards the online sellers and their products, and hence, increased online shopping engagement $[2,3,4]$. 


\subsection{Social Proof}

Social proof or informational social cue is a psychological phenomenon where people assume the actions of others are the correct behaviors to follow. The actions of others around us are important guides in a situation when decision makers are unclear about the value of the decision to be made [20]. Unconsciously, the collective information of the society or social community influences and contributes to our decisions. Regardless of how independent were think we are, our decisions to do or not to do certain things are conditioned by others around us. The force that influences our day to day decisions is known as social proof.

Social proof is much noticeable in social network platforms such as Facebook, Instagram and Twitter. When making a buying decision, many people need proof (authority) that a seller and its product are legitimate. In online shopping via networks, the proof can be obtained from reviews and recommendations by others. Social networks connect online shoppers directly with others to form a social community. The immediacy provided by social networks allows online shoppers to obtain and share products-related and sellers-related information within their social community. A market survey by Nielsen [15] reported that $92 \%$ of respondents worldwide trust recommendations by friends and families, and $70 \%$ of them ranked online consumer reviews as the second most trusted source of information. Amblee and Bui [2] discovered that electronic word-of-month (eWOM) among social community, such as online ratings and reviews, is a useful and effective signal of product reputation for a shopper yet to have a purchasing experience. The trust developed among the social community might possibly impact one's purchasing decision. Social media characteristics that facilitate the social interaction of consumers lead to increased trust and intention to buy [21,22]. Online businesses should consider using eWOM technologies as they are effective and primary source of social proof [2].

Nowadays, it's a trend for online sellers in social networks, such as Instagram, to promote their Instagram Shop (InstaShop) through reviews by famous celebrities, bloggers, or other reputable sellers. Famous celebrities' reviews were used by sellers to attract online shoppers to purchase their product [23]. Celebrity's endorsement is a signal to the consumers the seller and its product is trusted and has good reputation. Dzisah and Ocloo [24] found that social proof by means of celebrity's endorsement does not only influence on marketing promotions, but also on consumers' purchase or rebuying behaviors. A quasi-experiment research that examined Pepsi Cola commercials with and without celebrity endorsement discovered that celebrity endorsed advert has a significant influence on students' purchase intention [25]. Jain [26] found that celebrity endorsement in India helps in brand promotion, and thus, impact on sales. Therefore, businesses are recommended to grab the opportunity offers by celebrity endorsed adverts in order to expand their operations and promote their product.

In addition, social media platforms provide a 'liking' function. For example, Facebook 'like' button and Instagram 'follower' button indicate numbers of people following the business or sellers' online page. The amount of followers, fans, views and likes that offered by social networks are among important and effective tools to affect others' perception about the sellers. It is believe that the higher the number of 'like' or 'follower' of sellers, the higher the trust of shoppers on the legitimacy of particular sellers. A user on Twitter with a million followers is perceived as more trustworthy and reputable than a similar user with a thousand followers, resulting in faster growth of followers and higher engagement [27]. If a person 'like' social media seller page, they are more likely to buy the product, recommend the product to others and share the product content. For that reason, a ghost followers industry exists for the sole purpose of increasing social proof on social media [27]. However, Sitaram Asur et al. [28] empirically discovered that number of followers do not contribute to trend creation. Similarly, Thackeray et al. [29] found that 'liking' the page does not result in purchasing the product. They further explained that the insignificant relationship may be due to mismatch between the shared content and users' preference.

Based on the preceding literature discussion, we propose the following hypotheses for testing the effect on social proof techniques on buyers' intention to buy.

$$
\begin{aligned}
& H_{1} \text {-Consumers' purchase intention will be higher when number of followers is high rather than no followers } \\
& H_{2} \text {-Consumers' purchase intention will be higher when there is celebrity endorsement rather than no celebrity } \\
& \text { endorsement }
\end{aligned}
$$

$\mathrm{H}_{3}$-Consumers' purchase intention will be higher when there is social community recommendation rather than no social community recommendation

$H_{4}$ - There is significant difference of the impact of social proof techniques on consumers' purchase intention 


\section{METHODOLOGY}

\subsection{Design and Measure}

Experimental designs are highly functional, when seeking the associations between cause and effect in consumer research [30]. In this current study, an experimental design consisting of four between-subject conditions was applied. The manipulated independent variable is social proof (number of followers, endorsement by celebrities, recommendation by social community, and no information of social proof). The intention to purchase on social media is a measured variable. Treatment 1 showed the highest number of followers. Celebrity endorses the smart-phone in the treatment 2 and treatment 3 showed the condition where friends or recognized community tagging others in the Instagram. Treatment 4 is a control treatment which contains photos of smart-phone without any number of followers and endorsement from friends or celebrity. Participants were randomly assigned to one of the four conditions.

The fictitious company was depicted in each scenario under the name of "Gadjet Budget Enterprise" that sells cell phones on-line via Instagram. A fictitious company is created to control for any predisposition participants may have related to real companies and to minimize subject bias [31]. The selection of smart phones is explained by the fact that consumers especially university students are familiar with smartphones. The respondents' perceived on purchase intention were assessed with three questions based on the scale adapted from Chiu et al. [32]. A five-point Likert scale (from strongly disagree to strongly agree) was used for the questions. The Cronbach alpha of these three items was .88.

\subsection{Research procedure and respondents}

The subjects in this research are undergraduate students enrolled in information systems and accounting courses in one public University in Malaysia. Convenience sampling of university students is chosen to represent gender and the group of consumers of smart phone. The researcher contacted the instructors of the courses and asked their permission for students' participation in this study. Upon obtaining the consent, the respondents are randomly assigned to one of the four conditions of the experiment. First of all, researchers gave a brief explanation about the study. Respondents are given a sufficient time to read the scenario. In the scenario, the respondents have to imagine that they need to buy a smartphone for school work and leisure purposes. Their parents are giving them enough money for that purpose. The snapshot of Instagram seller and its product was provided to the respondents.

After reading the scenarios and the snapshot of the Instagram seller, respondents were asked to respond to manipulation checks regarding the scenario. Only those that answered the manipulation question right that count in this study. Then, participants were required to answer questions designed to assess their likelihood to buy from the Instagram seller. Finally, the respondents answered demographic questions, such as age and gender. Each scenario had around 26 to 33 number of respondents. Total of respondents was 122, which 19.7 percent male and 80.3 percent female. In terms of age groups, 89 percent of the respondents were between the ages of 18 and 22, 11 per cent in the 23-25 age groups.

\section{RESULTS}

A series of analysis of variance (ANOVA) were conducted in order to explore the impact of Instagram's social proof functions on purchase intentions (Table 1). Participants were divided into four groups according to the social proof functions in Instagram (Group 1: number of followers; Group 2: celebrity endorser; Group 3: social community recommendations and Group 4: control group). ANOVA tests revealed that there is a statistically significant difference in the mean of the Instagram social proof functions between the four treatment groups towards purchase intention $(\mathrm{F}=3.301, \mathrm{p}$ $=.05$ ). The results indicate that participants' intention to buy from Instagram seller is higher when there is recommendation from their social community, than where there is high number of followers or celebrity endorser or no social proof at all.

Table 1: ANOVA test

\begin{tabular}{llll}
\hline Variables & Mean & F & Sig \\
\hline Purchase Intention & & 3.301 & .023 \\
Number of followers & 7.687 & & \\
Celebrity endorser & 7.344 & & \\
Community recommendation & 9.461 & & \\
Control group & 7.314 & & \\
\hline
\end{tabular}

A Tukey post-hoc test reveals that the number of follower condition was significantly different from no number of follower condition. The number of follower condition was not significantly different from celebrity endorser and social community recommendation. The celebrity endorser condition was not significantly different from any celebrity endorser condition and 
community recommendation. The community recommendation condition was significantly different from no community recommendation. In addition, the results indicate that there is no significant difference among these three social proof conditions towards consumers' purchase intention.

Table 2: Post-hoc test

\begin{tabular}{llc}
\hline \multicolumn{1}{c}{ Group Experiment } & Group Experiment & Sig \\
\hline \multirow{2}{*}{ Number of followers } & Celebrity endorser & .954 \\
& Social community recommendations & 1.000 \\
& Control group & .029 \\
Celebrity endorser & Number of followers & .954 \\
& Social community recommendations & .969 \\
& Control group & .108 \\
Community recommendation & Celebrity endorser & .969 \\
& Number of followers & 1.000 \\
& Control group & .043 \\
\hline
\end{tabular}

\section{DISCUSSION AND CONCLUSION}

Social proof is prominent on social networks such as Instagram and Facebook; hence many online businesses have taken advantage by promoting and selling their products on social networks. The results of the experiment show that social proof techniques, specifically high number of followers and social community recommendations, does indeed play significant factors that impact on buyers' intention to buy from social media sellers. The results are consistent with prior studies that confirms eWOM (i.e., social community recommendation) and high number of followers are effective marketing tool to enhance product evaluation and hence, purchasing intention [2]. High number of followers is a signal to social media community that the particular sellers are legitimate and trusted although the supporters (i.e., followers) may be passively experienced. Similarly, positive recommendations help social community to learn about and have more favorable attitude towards unfamiliar products and sellers. Both techniques are equally effective in influencing consumers' purchasing intention, and hence, online sellers can choose either to increase the number of followers or to have more community recommendations.

On the other hand, having celebrity endorsement does not significantly different from not having celebrity endorsement. This indicates that celebrity endorsement is not relevant in the context of our study, unlike other studies (e.g., $[24,25])$. There are few possible reasons. First, the respondents were young people aged between 18 to 23 years old; who may not familiar with the chosen celebrities. Second, there is a possibility of mismatch between the product (i.e., mobile phone) and the celebrities' image. Therefore, it is suggested to online sellers to ensure the selected celebrities have the value and image that match with their brand and product.

Our study has some limitations. The use of students' data in one University only lacks of diversity and limits its generalizability. In addition, an experimental design research create artificial situation that do not always represent real-life situations. We shall replicate this study into real world social media shoppers to gauge holistic and realistic view of the influences of different social proof techniques on consumers' purchasing intention. Future research can also extend current study to investigate whether there is interaction effect among the social proof techniques.

\section{References}

1. J. Chen, H. Xu, \& A.B. Whinston, Moderated online communities and quality of user-generated content, Journal of Management Information Systems, 28, 2, pp. 237-268 (2011)

2. N. Amblee, and T. Bui, Harnessing the influence of social proof in online shopping: The effect of electronic word of mouth on sales of digital microproducts, International Journal of Electronic Commerce, 16, 2, 91-113 (2012)

3. P. Beatty, I. Reay, S.Dick, \& J. Miller, Consumer trust in e-commerce web sites, ACM Computing Surveys, 43(3), 1-46 (2011)

4. M. Zhou, \& D. Tian, An integrated model of influential antecedents of online shopping initial trust: Empirical evidence in a low-trust environment, Journal of International Consumer Marketing, 22(2), 147-167(2010)

5. M. Hajli, A study of the impact of social media on consumers, International Journal of Market Research, 56(3), 387404 (2014) 
6. Y. Chen, S. Fay, Q.Wang, The Role of Marketing in Social Media: How Online Customer Reviews Evolve, Journal of Interactive Marketing 25(2), 85-94 (2011)

7. D.H. Park, \& J. Lee, eWOM overload and its effect on consumer behavioral intention depending on consumer involvement, Electronic Commerce Research and Applications, 7, 4, 386-398 (2009)

8. N.A. Hashim, S. Mohd Nor \& H. Janor, Riding the waves of social commerce: An empirical study of Malaysian entrepreneurs, Malaysian Journal of Society and Space 12 issue 2,83 - 94 (2016)

9. A.M. Kaplan \& M. Haenlein, Users of the world, unite! The challenges and opportunities of social media, Business Horizons 53(1), 59-68 (2010)

10. B. Parr, (2008). Ben Parr's Entrepreneurial Musings. Retrieved from http://benparr.com/2008/08/itshttp://benparr.com/2008/08/its-time-we-defined-social-media-no-more-arguing-heresthe-definition

11. Mayfield (2008). What is social media, Retreived from http://www.icrossing.com/icrossing-what-is-social-media

12. V. Tapria \& P. Kanwar, Understanding Social Media. Varinder Tapria \& Priya Kanwar \& Ventus Publishing ApS, (2012)

13. Statista (2015). Retrieved from http://www.statista.com/statistics/278414/number-of-worldwide-social-network-users/

14. Internet Users Survey 2014 (2014). Retrieved from http://www.skmm.gov.my/skmmgovmy/media/General/pdf/Internet-Users-Survey-2014.pdf

15. Nielsen. (2014). E-commerce: evolution or revolution in the fast-moving consumer goods world? Retrieved from http://ir.nielsen.com/files/doc_financials/Nielsen-Global-E-commerce-Report-August-2014.pdf.

16. J. H.Wu \& S. C. Wang, What drives mobile commerce?: An empirical evaluation of the revised technology acceptance model. Information \& Management, 42(5), 719-729, (2005)

17. C. Wang \& P. Zhang, The evolution of social commerce: The people, management, technology, and information dimensions. Communications of the Association for Information Systems, 31(5), 1-23 (2012)

18. T. P. Liang \& E. Turban, Introduction to the special issue social commerce: a research framework for social commerce. International Journal of Electronic Commerce, 16(2), 5-14 (2011)

19. J. Shen, Social comparison, social presence, and enjoyment in the acceptance of social shopping websites. Journal of Electronic Commerce Research, 13(3), 198-212 (2012)

20. H. Rao, H.R. Greve and G.F. Davis, Fool's gold: Social proof in the initiation and abandonment of coverage by Wall Street analysts. Administrative Science Quarterly, 46, 3 (2001), 502-526 (2001)

21. T. P. Liang, Y. T. Ho, Y. W. Li \& E. Turban, What drives social commerce: The role of social support and relationship quality. International Journal of Electronic Commerce, 16(2), 69-90 (2011)

22. M. Hajli, A research framework for social commerce adoption. Information Management \& Computer Security, 21(3), 144-154 (2013)

23. R. Rahim, R. Aravinthan \& N.S. Hooi, Man dupes online shoppers. The Star, pp. 40 (2015, October 2)

24. W.E. Dzisah and C.E. Ocloo, Celebrity Endorsement and Consumer Buying Behaviour; Enhancing the Promotion Function of Marketing in the Central Business Area of Accra, Ghana. European Journal of Business and Management. Vol.5, No.25, 2013 (2013)

25. A. Apejoye, Influence of Celebrity Endorsement of Advertisement on Students' Purchase Intention. $J$ Mass Communicat Journalism 3:152 (2013)

26. V. Jain, Celebrity Endorsement And Its Impact On Sales: A Research Analysis Carried Out In India. Global Journal of Management and Business Research. Volume 11 Issue 4 (2011)

27. Devumi (2016). Retreived from https://devumi.com/social-proof-in-digital-success/

28. S. Asur, B. A. Huberman, G. Szabo, and C. Wang, Trends in social media - persistence and decay. In $5^{\text {th }}$ International AAAI Conference on Weblogs and SocialMedia, (2012).

29. R. Thackeray, B.L Neiger, A.K. Smith \& S.B. Van Wagenen, Adoption and use of social media among public health departments. BMC Public Health 12:242 (2012)

30. I. Assiouras, O. Ozgen \& G. Skourtis, The impact of corporate social responsibility in food industry in product-harm crises. British Food Journal, 115(1, SI), 108-123 (2013)

31. C.H. Cho, J. R. Phillips, A.M. Hageman \& D.M. Patten, Media richness, user trust, and perceptions of corporate social responsibility: An experimental investigation of visual web site disclosures. Accounting, Auditing \& Accountability Journal, 22(6), 933-952 (2009)

32. C.M.Chiu, C.C. Chang, H.L Cheng \& Y.H. Fang, Determinants of customer repurchase intention in online shopping. Online Information Review, Vol. 33 Iss 4 pp. 761 - 784 (2009) 